\title{
La Revolución Rusa en la memoria de los comunistas cordobeses
}

\section{The Russian revolution in the memory of the Communists from Córdoba}

\author{
Mariana Mastrángelo \\ Universidad de Buenos Aires \\ Universidad de Chilecito \\ Instituto de Estudios de América Latina \\ (Argentina) \\ mariana_mastrangelo@hotmail.com.
}

\begin{abstract}
Resumen
El siguiente trabajo tiene como objetivo explorar cómo quedó grabado en la Memoria de algunos militantes comunistas los sucesos de la Revolución Rusa y cuáles fueron las implicancias de este suceso que sacudió al mundo entero, en Córdoba, Argentina. Para su análisis, nos centraremos en las Memorias de tres militantes comunistas, que fueron pioneros en la conformación del Partido Comunista y del movimiento obrero cordobés, ellos son: Miguel Contreras, Jesús Manzanelli y Miguel Burgas. Estas Memorias fueron realizadas por el mismo Partido Comunista en la década de 1970 como una forma de homenajear a sus militantes más distinguidos, como así también, dejar un registro escrito de su experiencia y trayectoria.
\end{abstract}

Palabras Clave: Memoria - Revolución Rusa - Militantes comunistas 


\begin{abstract}
The following paper is aimed to explore the memory of the Russian revolution in some Communist militants. Furthermore, it is analyzed the implications of this events - that shocked the whole world- in the province of Córdoba (Argentina). The investigation is focused on the memories of three Communist militants, who were key actors in the formation of the Communist Party and the labor movement from Córdoba: Miguel Contreras, Jesús Manzanelli and Miguel Burgas. Communist Party published these memories in the 1970s as a way of paying homage to its most distinguished militants, as well as recording in writing their experience and trajectory.
\end{abstract}

Key Words: Memory - Russian revolution - Communist.

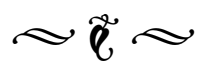

\section{Introducción}

Eric Hobsbawm sugiere en su libro de ensayos Revolucionarios que:

La Revolución Rusa fue la primera revolución proletaria, el primer régimen de la historia que emprendió la construcción del orden socialista, la prueba tanto de la profundidad de las contradicciones del capitalismo, engendradora de guerras y crisis, como de la posibilidad -y la certezade que la revolución socialista iba a triunfar. Fue el comienzo de la revolución mundial. El comienzo del nuevo mundo. ${ }^{1}$

La idea de "comienzo de un nuevo mundo", de la instalación del "orden socialista" fue una bocanada de esperanza no sólo para sus coterráneos, sino para el mundo entero que seguía los sucesos acaecidos en esas tierras tan distantes con especial atención.

La revolución pronto se hizo sentir en la Argentina, sacudiendo tanto a la izquierda

1.HOBSBAWM, Eric J., Revolucionarios. Ensayos contemporáneos, Editorial Ariel, Barcelona, 1978, pp. $13-14$.

118 como al movimiento obrero y sindical. Adoptaron su bandera y la hicieron propia, identificándose con su ideario. Por ejemplo, en el primer documento que emitió el naciente Partido Socialista Internacional en el año 1919, se hace alusión a la Revolución Rusa en varios párrafos, en especial, destacamos la siguiente cita que resume el espíritu de la época y la voluntad de sus militantes:

Un ardiente e impetuoso soplo revolucionario parece cruzar triunfante por el planeta. Ha comenzado en Rusia y se extiende hacia todos los rincones del mundo. Su móvil: la instauración del socialismo. Con la mirada elevada en tal alto ideal queremos ser en esta sección de América, los agentes eficientes, activos, de esta hondísima transformación revolucionaria. ${ }^{2}$

En este trabajo nos proponemos indagar cómo quedó grabado el ideario de la Revolución

2. Véase el Memorial dirigido a todos los Partidos Socialistas por el Partido Socialista Internacional en CAMPIONE, Daniel, El Comunismo en Argentina. Sus primeros pasos, Centro Cultural de la Cooperación Floreal Gorini, Buenos Aires, 2005, p. 105. 
Rusa en la memoria de los primeros militantes del naciente Partido Socialista Internacional, poco tiempo después Partido Comunista (en adelante PC) y cuáles fueron las implicancias de ésta en su proceso de politización. En particular, nos centraremos en la provincia de Córdoba, donde el PC tuvo injerencia desde temprano en estos jóvenes que veían en el:

Maximalismo (nombre que se daba a la Revolución Rusa en ese momento) la consigna revolucionaria de las grandes masas que querían hacer realidad en cada país la Revolución Social. ${ }^{3}$

¿Cómo vivieron este acontecimiento los obreros y militantes de este nuevo partido en Córdoba? ¿Por qué la revolución de octubre tuvo ese impacto? Y por último ¿En qué medida determinó su ingreso a la militancia de izquierda? Estas preguntas recorrerán este trabajo, haciendo especial énfasis en la Revolución Rusa y en los vestigios que dejó la misma en jóvenes que se iniciaban en la militancia.

Para el estudio de estos interrogantes nos centraremos en las memorias que el PC elaboró a partir de la década de 1970. Este partido comenzó a recoger la experiencia de sus más distinguidos militantes y los reunió en una colección que la denominó Testimonios. Estos relatos, en general, fueron recuperados ya en la última etapa de la vida de estos comunistas. Estas biografías tuvieron un carácter de "homenaje" a sus militantes más destacados, y en las mismas se resalta, por sobre todo, su militancia en el partido. Es así que la Revolución Rusa ocupa

3. MANZANELLI, Jesús, La vida de un dirigente obrero y comunista cordobés, Colección Testimonios, Buenos Aires, 1971, p. 18. un lugar destacado en estas crónicas. En el caso cordobés, se realizaron tres memorias, la de Jesús Manzanelli (1971), Miguel Contreras (1978) y Miguel Burgas (1985), y nos basaremos en ellas para el tema que nos interesa abordar.

Las memorias de estos militantes comunistas tienen características de testimonios orales ya que fueron grabadas y luego transcriptas con sus correcciones. De la misma manera que en el momento de la entrevista se construye un tipo de fuente que está atravesada por la subjetividad del entrevistador $y$ del entrevistado, los relatos de estos obreros y militantes también están cruzados por la visión de mundo de quienes las produjeron. En este sentido, más allá de la veracidad de la información que nos proporcionan y teniendo presente que las mismas fueron hechas con el objetivo de ser un medio de propaganda partidaria, nos serán de utilidad para observar cómo un hecho puntual como fue la Revolución Rusa quedó inscrito en la experiencia de estos militantes. ${ }^{4}$

\section{Orígenes del Partido Socialista Internacional}

En nuestro país, el impacto que se gestó a partir de la Revolución Rusa propició cambios importantes que se venían produciendo dentro del movimiento obrero y de la izquierda, en particular, del Partido Socialista. En el mismo año de la revolución,

4. Véase sobre las temáticas de: Memoria, biografías y autobiografías, los textos sugerentes en SÁ AVELAR, Alexandre y BISSO SCHMIDT, Benito (compiladores) Grafía da vida. Reflexóes e experiencias com a escrita biográfica, Letra e Voz, Sao Paulo, 2012. 
1917, se dio una profunda crisis dentro de este partido, que tuvo su culminación en el congreso realizado en el salón Verdi del barrio de la Boca $^{5}$ los días 28 y 29 de abril. En el mismo se enfrentaron dos tendencias que, según plantea Emilio Corbière, conmovieron a todos los partidos socialistas agrupados en la II Internacional: la socialdemocracia por un lado y la marxista revolucionaria por el otro. ${ }^{6}$ Esta división dentro del socialismo argentino dio como resultado la escisión del ala de izquierda, que el 5 de enero de 1918 fundó el Partido Socialista Internacional, que dos años más tarde adoptaría el nombre de Partido Comunista. Los socialistas internacionales no actuaron, siguiendo a Corbière, al influjo de la Revolución Rusa, transportando mecánicamente una experiencia vivida en otro país, a la Argentina. Fue un movimiento socialista de izquierda que se originó, desarrolló y consolidó dentro del Partido Socialista Argentino. El mismo tuvo un importante ascendiente obrero, que quedó evidenciado en la actividad que llevó a cabo el Comité de Propaganda Gremial (que funcionó de 1914 a 1917) basada en la politización de la lucha sindical. ${ }^{7}$

Un dato distintivo de este grupo de militantes fue su juventud. Por esta razón, con los "internacionalistas", como se los denominaba, se fueron también la Federación de las Juventudes Socialistas. Asimismo, un núcleo importante de veteranos del Partido

5. Lugar emblemático donde se llevaban a cabo las asambleas obreras de la época.

6. CORBIÈRE, Emilio, Orígenes del comunismo argentino, Centro Editor de América Latina, Buenos Aires, 1984, p. 13. También véase sobre este tema: ISCARO, Rubens, Origen y desarrollo del movimiento sindical argentino,

Editorial Anteo, Buenos Aires, 1958, capítulo VI.

7. Ibídem.

120
Socialista, en particular, el grupo que había militado en el movimiento de los socialistas alemanes reunidos en el Club Vorwärt, siguieron a los jóvenes internacionalistas.

Entre los integrantes del nuevo Partido Socialista Internacional se encontraban tres cordobeses que tuvieron un rol protagónico en la conformación del Partido Comunista en Córdoba. Ellos fueron: Pablo López, Miguel Contreras y Julián Deanquín.

\section{E1 naciente Partido Comunista y su protagonismo en la conformación del movimiento obrero cordobés}

Para comprender la influencia de la Revolución Rusa en Córdoba es necesario hacer un breve recorrido por la historia del comunismo cordobés, que se desarrolló y consolidó en las décadas de 1920 a 1930. Los comunistas tuvieron, desde temprano, un lugar preponderante en el movimiento obrero de la provincia. ${ }^{8}$ Desde el año 1917 , a partir de la huelga ferroviaria, se dio un intenso proceso de movilización y organización entre los obreros del calzado, de la madera, gráficos, albañiles, pintores, caleros y molineros. Hacia esa época se destacaban tres referentes entre el movimiento obrero cordobés: el tipógrafo Pablo B. López (organizador del Sindicato

8. Véase sobre el accionar del PC en Córdoba: MASTRÁNGELO, Mariana, Rojos en la Córdoba obrera, 1930-1940, Imago Mundi, Buenos Aires, 2011. También CAMARERO, Hernán, A la conquista de la clase obrera.

Los comunistas y el mundo del trabajo en la Argentina, 1920-1935, Editorial Siglo XXI, Buenos Aires, 2007. 
de Artes Gráficas) ${ }^{9}$, Pedro Magallanes (uno de los creadores de la Unión General de Obreros del Calzado) y el tapicero y gráfico Miguel Contreras. Los tres pertenecieron a la tendencia de izquierda del Partido Socialista y estuvieron entre los fundadores del PSI (en adelante, Partido Socialista Internacional) primero, y del PC, después, partido al que luego se sumaron los hermanos Jesús y José Manzanelli, Miguel Burgas, Rufino Gómez, Antonio Maruenda y Leonardo Peludo. En 1918 estalló la huelga de los trabajadores del calzado que consolidó el poder de la Federación Obrera Local de Córdoba (en adelante FOLC) constituida por la mayoría de los gremios de esa ciudad. Luego se extendió la organización sindical hacia el interior de la provincia. Todo se daba en un contexto de agitación popular, influida por la Reforma Universitaria. Fueron los comunistas quienes durante 1918 impulsaron la unificación de unos cuarenta sindicatos en la FOLC. Su crecimiento en los primeros años fue muy importante y se fundaron nuevos gremios en la capital (tranviarios, Luz y Fuerza y Cerveceros) y varias federaciones locales en distintas ciudades. Los dos dirigentes principales de la FOLC fueron Pablo López y Miguel Contreras. La federación no se unió a ninguna de las dos FORA ${ }^{10}$ existentes en ese

9. Véase una breve biografía de este obrero gráfico realizada por FERRERO, Roberto, "Pablo B. López, líder del proletariado de Córdoba”, en Revista Deodoro, Córdoba, 2010, No 3, p.11.

10. FORA fue una federación obrera argentina fundada el 25 de mayo de 1901 con el nombre de Federación Obrera Argentina y denominándose FORA a partir de su cuarto congreso en agosto de 1904. Tuvo una destacada actuación hasta los años treinta. A partir de su quinto congreso aprobó y recomendó a todos sus adherentes, la propaganda e ilustración acerca de los principios económicos y filosóficos del comunismo anárquico. momento en el país. En el año 1919, la FOLC se transformó en Unión Obrera Provincial (en adelante, UOP), organización que lideró los conflictos urbanos y rurales que sacudieron la provincia hasta el año 1921. Desde 1922, mientras la UOP se constituía en estructura orgánica de la Unión Sindical Argentina (en adelante, USA), ${ }^{11}$ comenzó un proceso de debilitamiento, contemporáneo al cierre del período huelguístico. ${ }^{12} \mathrm{~A}$ raíz de este reflujo de la lucha obrera se dio un enfrentamiento entre los sindicalistas revolucionarios y los comunistas por el dominio de la federación provincial, imponiéndose estos últimos. Es recién en los años 1925-1926 que la UOP volvió a recobrar parte de su fuerza. En ese período, el PC cordobés mantuvo su presencia dominante en el movimiento obrero cuya característica sobresaliente fue la de ser una organización integrada y dirigida, mayoritariamente, por trabajadores. Esta consolidación como fuerza política puede evidenciarse en las elecciones del año 1924, 1925 y 1928. En 1924 el partido consiguió un diputado provincial, Miguel Burgas, quien asumió a pesar del intento de la Iglesia Católica por impedirlo. En las elecciones municipales de noviembre de 1925, el PC se presentó en el interior cordobés como

En 1915, la FORA eliminó la adhesión al comunismo anárquico, lo que llevó a la desafiliación de varios sindicatos anarquistas, creándose dos centrales: la FORA del V Congreso (anarquista) y la FORA del IX Congreso (mayoría sindicalista y minorías socialista y comunista).

11. La Unión Sindical Argentina (USA) fue una central sindical dominada por la corriente sindicalista revolucionaria fundada en Argentina en 1922. Se originó en la fusión de la FORA con varios sindicatos autónomos. Editó el periódico llamado Bandera Proletaria.

12. CAMARERO, Hernán, A la conquista ..., Op. Cit., 97. 
una nueva alianza política denominada Block Obrero y Campesino. Esta alianza fue producto de un plan estratégico ideado por los dirigentes comunistas cordobeses en vísperas de una renovación parlamentaria y comunal en la provincia. El objetivo era implantar una acción propagandística destinada a sumar a integrantes de la clase obrera y campesina. Dicho plan se denominó: "Campañas electorales y propaganda en el interior" y sus resultados fueron disímiles. Por ejemplo, este Block Obrero y Campesino se presentó en Río Cuarto, Huinca Renancó, Las Varillas, Cañada Verde y General Roca. En estas últimas tres localidades el partido alcanzó sus primeros concejales. En el año 1928, esta alianza ganó las elecciones municipales en Cañada Verde. José Olmedo, peón rural y analfabeto, se convirtió en el primer intendente comunista del Block Obrero Campesino en una ciudad del interior cordobés. ${ }^{13}$

Durante la segunda mitad de los años veinte, el PC hegemonizó el Consejo Federal de la UOP (los secretarios generales fueron Antonio Maruenda y José Manzanelli), lo mismo que la conducción de la mayor parte de la quincena de sindicatos que la integraban en aquel entonces, no sólo de la ciudad de Córdoba, sino también del interior de la provincia. En esos años, la relación entre los sindicalistas y comunistas se hizo muy difícil: la USA acusaba a la UOP de poseer manejos sectarios y excluyentes y de quedar en completa subordinación al PC. Desde

13. Véase CORBIÈRE, Emilio, Orígenes..., Op. Cit. También: DANIELE, Flavia, Historia de la primera intendencia comunista de la provincia de Córdoba. El Block obreros y campesinos de Villa Huidobro: 1925-1928, Tinta Libre, Córdoba, 2011.

122
1927, las relaciones entre la UOP y la USA estuvieron deterioradas y la primera actuaba con autonomía de la central. A mediados y fines de 1928 se produjo una recomposición de estas relaciones, correlato del proceso de acercamiento que se verificaba entre las direcciones de la USA y del PC. Pero pocos meses más tarde, a principios del año 1929, con la aplicación de la política del tercer período, estrategia que la Internacional Comunista (IC) impuso a todas sus secciones en el año 1928 y que significó un giro radical en la política sindical del PC. A partir de ello, el PC puso en marcha la creación de estructuras sindicales "clasistas y revolucionarias”, dejando de participar en las demás organizaciones obreras. Dentro de este nuevo contexto, la UOP se alejó de la USA y adhirió en bloque al Comité de Unidad Sindical Clasista (CUSC) y a la Confederación Sindical Latino Americana (en adelante, CSLA), al tiempo que intentó promover conflictos en la ciudad y el interior de la provincia. Al finalizar la década de 1920, la protesta que trascendió el orden local fue la huelga de 1929 en San Francisco. En este año, la huelga denominada el "Tampierazo" en esta ciudad del interior cordobés, tuvo como organizador y movilizador del movimiento huelguístico al PC que paralizó a esa localidad por más de tres meses. Principalmente, la figura de José Manzanelli fue determinante para la conformación del Sindicato de Oficios Varios, de la Asociación Femenina Comunista y de la Juventud Comunista de esta ciudad. ${ }^{14}$

14. MASTRÁNGELO, Mariana, Cultura y politica en la Argentina: los comunistas en la buelga de 1929 en San Francisco, una ciudad del interior de Córdoba, Facultad de Filosofía y Letras, Universidad de Buenos Aires/Editorial Imago Mundi, Buenos Aires, 2006. 


\section{La Revolución Rusa en la memoria de los comunistas cordobeses}

El primer testimonio que abordaremos es el de Miguel Contreras, obrero de varios oficios como panadero, canillita, tapicero y gráfico. En 1913, Contreras se afilió al Partido Socialista y en el año 1918, fue uno de los fundadores del Partido Socialista Internacional en Córdoba, luego PC. Junto a su maestro, el gráfico Pablo López, tuvo un papel decisivo en la organización del movimiento obrero cordobés, desde la conformación de la FOLC hasta la consolidación de la UOP, donde en la década de 1930, el PC tuvo un gran protagonismo, como ya se mencionó en párrafos anteriores. Asimismo, dentro del PC, a nivel provincial como nacional, tuvo una importante trayectoria que lo llevó a ocupar cargos en el Comité Central. A nivel internacional, tuvo un rol central en la organización del Primer Congreso Sindical Continental que se realizó en Montevideo, Uruguay, en el año 1929. ${ }^{15}$ De allí surgió la CSLA, donde se desempeñó como secretario general. ${ }^{16}$

Miguel Contreras recuerda en sus memorias: "Cuando en octubre de 1917 estalló la Revolución Rusa, aquí fue una fiesta general... La toma del poder por los soviets y la salida de la guerra despertaron gran entusiasmo. Nosotros le decíamos a la gente 'esa es nuestra bandera'". ${ }^{17} \mathrm{El}$ entusiasmo expresado por Contreras, también quedó registrado en los periódicos de la época, como por ejemplo,

15. Véase sobre la biografía de Miguel Contreras:

CONTRERAS, Miguel, Memorias, Buenos Aires, Colección Testimonios, Buenos Aires, 1978. También TARCUS, Horacio, Diccionario Biográfico de la izquierda argentina, Emecé Editores, Buenos Aires, 2007.

16. La CSLA existió hasta el año 1936.

17. CONTRERAS, Miguel, Memorias..., Op. Cit., p. 22. en la prensa obrera y de izquierda, de la misma manera que en los periódicos locales como La Voz de San Justo de San Francisco y El Trabajo de Río Cuarto.

Retomando su testimonio, éste planteaba que: "ellos, que ya estaban militado en el socialismo, tomaron este hecho como una bandera propia". ${ }^{18} \mathrm{La}$ apropiación del ideario revolucionario fue determinante ya que posicionó a este militante y la fracción radical que representaban, como la vanguardia de la izquierda y a ellos como los verdaderos revolucionarios.

Asimismo, para Contreras, la Revolución Rusa cambió radicalmente la realidad local. En Córdoba, en las primeras décadas del siglo $\mathrm{XX}$, ya existían centros socialistas, en secciones predominantemente obreras. En todas las secciones de la ciudad Capital, como en el interior cordobés como Las Varillas, Jesús María, Malagueño y La Calera, ${ }^{19}$ se impuso la tendencia de izquierda que López y Contreras lideraban. La peculiaridad de Córdoba fue que si bien no pudieron mandar (por razones económicas y por las luchas intestinas dentro de la FOLC) un representante a Buenos Aires para participar del Congreso que dio vida al PSI, todos los centros socialistas locales formaron parte de la nueva agrupación política marxista. Asimismo, la FOLC fue la primera de su carácter que fue orientada por el nuevo partido. ${ }^{20}$ En sus memorias, Contreras, luego

18. Ídem, p. 23.

19. Estas ciudades del interior cordobés eran muy pequeñas, la primera sección que se abrió del Partido Socialista fue en Jesús María.

20. CONTRERAS, Miguel, Memorias..., Op. Cit., pp. 23-24. 
de mencionar los cambios ocurridos con la Revolución Rusa, realiza un recuento de cómo fue consolidándose la postura del $\mathrm{PC}$ en el mundo obrero y sindical cordobés. Siguiendo el relato del militante comunista, en el 1918 se dio una de las huelgas más importantes en la ciudad de Córdoba que estalló en la fábrica de calzados Tettamanti. La FOLC organizó la solidaridad de centenares de huelguistas, entre ellos, hombres y mujeres que mantuvieron el movimiento por dos meses. También ese año la FOLC organizó una huelga general, que fue un éxito, paralizando a toda la ciudad. Este movimiento reivindicativo inauguró una nueva forma de organización sindical. Se dejaron de lado las huelgas espontáneas planteadas por los anarquistas de la FORA del V Congreso, dándose lugar a la organización y programación de las luchas. En este contexto de conflicto obrero, se destacó el protagonismo que tuvo el Partido Socialista Internacional recién fundado en Córdoba. Otro elemento nuevo que se desprende de este movimiento fue la solidaridad estudiantil, conformándose un frente obrero-estudiantil. La Federación Universitaria de Córdoba (en adelante, FUC) adhirió a la corriente huelguística, designando a oradores para participar del mitin que organizó la FOLC. Ante este movimiento de masas llevado adelante por la FOLC y la FUC, el obispo de Córdoba, Zenón Bustos y Ferreira, en su pastoral del día 22 de noviembre de 1918, alertaba sobre la difusión del "maximalismo" en la provincia. ${ }^{21}$ También la agrupación "Córdoba Libre", compuesta por los egresados reformistas, que fueron también entusiastas de la Revolución Rusa, apoyaron la huelga eligiendo a Deodoro Roca y Saúl Taborda como oradores para el acto

21. BILSKY, Edgardo, La Semana Trágica, Centro Editores de América Latina, Buenos Aires, 1984, p. 50. ya mencionado. El acto fue multitudinario, donde se calculaba que concurrieron más de veinte mil personas. De esta alianza obreroestudiantil se desprendió un nuevo vínculo, siendo la Reforma Universitaria y el grupo de egresados que la llevaron adelante, una de las bases de apoyo más fuerte que acompañó al movimiento obrero cordobés durante este período. ${ }^{22}$

En este recorrido por las primeras páginas de las memorias de Miguel Contreras, encontramos, como pudimos observar, una referencia fugaz a los sucesos que trajeron aparejados la Revolución Rusa, tanto en su vida personal, como en el nacimiento del $\mathrm{PC}$ en Córdoba. Si bien se advierte que la revolución significó un cambio a nivel mundial y también local, su relato se estructuró en torno a su militancia y al protagonismo que tuvo él mismo en la organización sindical y del movimiento obrero cordobés, como uno de los pilares fundadores de la FOLC y luego, UOP. En esta estructura narrativa sobre la vida de Contreras, lo que se vislumbra es un testimonio que tiene un claro objetivo propagandístico, donde el partido decidió exaltar, a través de este testimonio, la figura de uno de sus militantes más significativos de la época. Por esta razón, en su testimonio no encontramos dudas, temores ni elementos subjetivos que den cuenta de cómo era este dirigente comunista. En este sentido, el mensaje que nos transmiten sus memorias dan cuenta de cómo debía ser un verdadero militante comunista en esos primeros años de conformación del partido: "un soldado de la causa".

22. Véanse los meses de enero y febrero de $\mathrm{La} \mathrm{Voz} \mathrm{del}$ Interior del año 1918. También CONTRERAS, Miguel, Memorias..., Op. Cit., pp. 29-35. 
Distintos son los dos testimonios que indagaremos a continuación a partir del análisis de las memorias de Miguel Burgas y de Jesús Manzanelli. En los mismos, si bien se destacan hechos personales que se encuentran imbricados en un contexto local y nacional, como en el ejemplo de Contreras, lo que dejan entrever sus relatos son elementos más personales, que podemos conjeturar, se vinculan al hecho de que ambos provenían de una ciudad pequeña como Jesús María en el caso de Burgas, o de la zona rural en el de Manzanelli. Su adhesión a un partido de izquierda, y el proceso que transitaron hasta llegar al mismo, quedó evidenciado en sus testimonios como elementos determinantes que ayudaron en su ingreso a la militancia. También es de remarcar que tanto Burgas como Manzanelli, se incorporaron al PC luego de su fundación, y si bien su quehacer dentro del partido fue importante, no tuvieron la trascendencia nacional e internacional que logró Contreras, a pesar de que, en el caso de Burgas, fue el primer diputado comunista de la Argentina en el año 1924.

Lo que observaremos en los siguientes testimonios es cómo la crisis imperialista de la Primera Guerra Mundial y luego la Revolución Rusa fueron claves en la politización de estos obreros comunistas en Córdoba.

El segundo testimonio que analizaremos es el de Miguel Burgas. Obrero gráfico, de la construcción y dirigente gremial. Desde su cargo legislativo impulsó las leyes sobre los peones rurales, la regulación del sábado inglés, el descanso dominical y el horario nocturno de los obreros panaderos. ${ }^{23}$ Participó

23. Estas leyes las trabajaron conjuntamente con los luego en la huelga de la construcción en el año 1936, y en la guerra Civil Española. Asimismo, fue editor durante muchos años del periódico comunista La Internacional. $\mathrm{Su}$ ingreso primero en el Partido Socialista y luego en el PSI sucedió en Jesús María, un pequeño pueblo del interior cordobés. ${ }^{24} \mathrm{En}$ sus memorias, aparece su iniciación en la política de la siguiente manera:

Mis padres compraron un hotel en Jesús María. En el hotel trabamos relaciones con personajes importantes, como los miembros del Partido Socialista ... Por entonces me apasionaba el proceso de la guerra imperialista de 1914. Leía todo lo referente a ella acompañado por un viejo radical; hasta reconstruíamos los planos estratégicos y todo lo concerniente al aspecto militar. Con los demás parroquianos lo que hacíamos era discutir acaloradamente..$^{25}$

En el testimonio de este obrero comunista queda reflejada la forma en que muchos de los militantes de esta generación comenzaban su vida política. En este sentido, el contexto de la Primera Guerra Mundial y luego la Revolución Rusa sirvió como medio de politización. Fue a partir de estas acaloradas discusiones que Burgas conoció a un sastre socialista de nombre Santerini, quien le alcanzó los primeros números del periódico

diputados socialistas Ricardo Belisle, Juan Remedi y Edmundo Tolosa, este último reemplazado por Isidro Oliver.

24. Véase sobre la biografía de Miguel Burgas: BURGAS, Miguel, El primer diputado comunista. Año 1924, Editorial Anteo (Colección Testimonios), Buenos Aires, 1985.

También: TARCUS, Horacio, Diccionario Biográfico..., Op. Cit.

25.BURGAS, Miguel, El primer diputado..., Op. Cit., pp. 12-13. 
La Vanguardia. El sastre, a través del interés del joven por la guerra recuerda Burgas, le manifestó: "si queres saber cosas de la guerra, tenes que leer esto”. Así fue como comenzó el proceso de politización de este militante, por medio de la lectura del periódico socialista y discusiones con aquel sastre y con un zapatero de origen italiano de nombre Pafún, quien había participado en el partido socialista italiano. Éste último le habría sugerido que se afiliara al Partido Socialista; según Burgas un día le dijo: "Por qué no te afilias al Partido, si vos sabes más que nosotros, podrías ser un buen socialista, lees e interpretas cosas que nosotros, socialistas, desconocemos". ${ }^{26}$ El ejemplo del zapatero, demuestra, por un lado, que inmigrantes de distintas nacionalidades, en particular italianos, influyeron de manera decisiva en las prácticas políticas y culturales de pequeños pueblos y ciudades del interior cordobés. Por el otro lado, nótese que en la argumentación del zapatero Pafún éste convence al joven Burgas a partir de un criterio cultural izquierdista, ${ }^{27}$ cuando remarcaba que "podrías ser un buen socialista, lees e interpretas cosas que nosotros, socialistas, desconocemos". Aquí lo que descubre el inmigrante italiano en el joven Burgas es que él ya era socialista, incluso antes de las lecturas del periódico socialista y las discusiones acaloradas con el sastre y el zapatero. Cuando nos referimos a cultura izquierdista, queremos destacar que la cultura se expresa no sólo en el arte o en las instituciones, sino también en el modo de percibir el mundo. De esta manera, diría Raymond Williams, se establecen estructuras de sentimiento que están implícitas en estas

26. Ídem, p. 14.

27. Véase sobre cultura izquierdista: MASTRÁNGELO, Mariana, Rojos..., Op. Cit.

126 personas, que se encuentran embebidas de valoraciones éticas y morales. Siguiendo al autor, estructuras del sentir son sinónimos de conceptos más formales como "concepción del mundo" o "ideología. ${ }^{28}$ Estos elementos se hacen presentes en el proceso de politización de estos militantes comunistas.

Asimismo, su madre también tuvo un proceso de politización en el hotel familiar, Burgas recuerda que ella:

Era una mujer de convicciones católicas, pero la fuimos ganando con nuestro ejemplo militante. Ella no llegó a afiliarse, pero era una verdadera amiga de los compañeros a pesar de su edad. Todas las delegaciones contaban con su colaboración, incluso el mismo Rodolfo Ghioldi que pernoctó unos días en el hotel. Ella conocía toda nuestra actividad. Ella siempre nos decía: 'cualquier cosa que necesiten, si llegan a hacer un acto, yo me encargo de la comida'... Cuando el hambre provocado por la guerra civil en la naciente Rusia Soviética, se nos planteó el problema de adoptar niños a distancia. Nuestro Centro tomó dos y mi madre uno de ellos. Ella pagó todos los meses la cuota convenida. ${ }^{29}$

Como puede observarse, en la memoria de Burgas, su madre también fue permeable a las nuevas ideas que él mismo iba experimentando. Si recordamos la novela $L a$ madre de Máximo Gorki, podemos hacer una analogía de este mismo despertar a la política. Lo que vive el hijo es también vivenciado por su madre. Asimismo su relato contiene una

28. WILLIAMS, Raymond, Marxismo y literatura, Ediciones Península, Barcelona, 1980.

29. BURGAS, Miguel, El primer diputado..., Op. Cit., pp. 17-18. 
estimación positiva sobre la militancia en el partido. Los valores morales del partido eran fundamentales para este militante ya que en palabras de él, su madre "en todo momento nos agradecía su reconocimiento por haberla ayudado a experimentar ese cambio en su modo de pensar y ver el mundo". ${ }^{30}$

Sin embargo, antes que su madre, él experimentó ese cambio en su percepción y en el modo de ver el mundo. La Gran Guerra fue el inicio de una toma de conciencia para Burgas. Este hecho puntual, fue uno de los detonantes en la politización de militantes de izquierda de la época. Se suma al conflicto bélico, la lectura en este proceso, como ya hemos indicado. Recuerda Burgas que "el material básico de nuestras lecturas era la prensa que llegaba al hotel, La Nación o La Prensa". Luego se sumaría La Vanguardia que le pasaba el sastre Santerini. Asimismo, habían pedido el Manifiesto Comunista y otros libros, que según Burgas "leía con fruición metido detrás del mostrador". Por el año 1918, Burgas escribió a París solicitando un ejemplar de L'Humanité. Con el tiempo llegó a tener cuenta corriente con el periódico del Partido Comunista Francés y cuando pedía un material se lo mandaban por correo. Asimismo, tuvo que aprender francés para poder leer en ese idioma la prensa partidista $y$ otras publicaciones que encargaba por correspondencia. Lo que subyace en su relato es que el ideario de la Revolución Rusa sería la confirmación de lo que leía y de lo que sentía ya que se convierte, de esta manera, en una reivindicación obrera.

En su narración, Burgas llama la atención sobre que "todo lo que relata ocurría en una

30. Ídem, p. 18. pequeña comunidad del interior del país, tan lejos de Buenos Aires, en la década de 1920". ${ }^{11}$ Su observación cobra sentido ya que existía y persiste en la actualidad una fuerte tradición que considera que el desarrollo de las tendencias de izquierda ocurrió sólo en los grandes centros urbanos, en este caso para la época, Buenos Aires, Rosario y Córdoba Capital, en menor medida. Sin embargo, se dio contemporáneamente en el interior de la Argentina. ${ }^{32}$ Jesús María era un microcosmos de esta realidad, donde Burgas se politizó. En el siguiente párrafo describe cómo ingresó a militar en el Partido Comunista:

También en Jesús María fue dibujándose internamente una fracción internacionalista dentro del socialismo. Pero, y esto es muy importante, esta fracción no recibió influjo alguno del movimiento que paralelamente se desarrollaba en Buenos Aires... Los opositores a la guerra llegamos a ser mayoría absoluta en el Centro Socialista local. De esta manera conquistamos la dirección del mismo, eligiendo como secretario a un compañero de apellido Decanini, que había sido quintero ${ }^{33}$ en la estancia de Roca.Y aquí viene otra anécdota significativa. La policía se pone de parte de la minoría reformista desplazada del Centro y ordena a los flamantes dirigentes la devolución del local a aquellos. Los jóvenes dirigentes marchan entonces a Córdoba y allí establecen su primer

31. Ídem, p. 16.

32. Véase sobre cultura obrera en el interior cordobés: MASTRÁNGELO, Mariana, Rojos..., Op. Cit. También: MASTRÁNGELO, Mariana, "Biografía de Miguel Burgas, el primer diputado comunista argentino" en Godhino Paula, Fonseca Inés, Baía Joao (coordinadores) Resistencia ely Memoria. Perspectivas iberoamericanas. (Documento electrónico), IHC-FCSH/ UNL, Lisboa, 2014, pp. 142-151.

33. Un quintero es un pequeño productor agrícola. 
contacto con el núcleo internacionalista del Partido Socialista. 'Nosotros los apoyamos fraternalmente', fue la respuesta del viejo [Pablo] López, patriarca y fundador del Partido Comunista... Así fue que cuando retornamos a Jesús María ya nos considerábamos integrantes del Partido Socialista Internacional... ¡Que los reformistas se guarden el local! Nosotros somos el Centro Comunista de Jesús María. ¡Los verdaderos revolucionarios! ${ }^{34}$

Como expresa Burgas, en Jesús María también se vivieron las tensiones existentes en el Partido Socialista de la época, y ellos representaban esa fracción contestataria, internacionalista como él mismo denominaba. Ellos se sentían "verdaderos revolucionarios". Esta connotación positiva sobre ellos mismos da cuenta de los valores morales y éticos que tenía Burgas en ese momento. Asimismo, esta apreciación podríamos contextualizarla en lo que representó el PC para estos jóvenes que se incorporaron en sus filas. Hernán Camarero, al analizar los periódicos de fábricas editados por los comunistas en la década de 1920, encuentra que:

Aparecen una serie de valores y nociones, como la valentía, la honradez, la dignidad, la humillación que se sufre de los poderosos, el portador de la justicia, que operan a manera de construcciones imaginarias que conforman al 'mundo de los obreros'; el atropello, el vocabulario soez y despectivo, la arbitrariedad, la alcahuetería, la discriminación racial, junto a la explotación, claro está, son las características del mundo de 'ellos', de los jefes y capitalistas..$^{35}$

34. BURGAS, Miguel, El primer diputado..., Op. Cit., pp. 16-17.

35. CAMARERO, Hernán, A la conquista..., Op. Cit., 128
Siguiendo a Camarero, estos valores enaltecieron las características del nuevo militante obrero comunista en la Argentina en la década de 1920. A diferencia de socialistas y sindicalistas que buscaban márgenes de negociación con la patronal, los comunistas siempre pretendían enfrentarla, convocando al despertar de la conciencia y llamando a comenzar o reiniciar la lucha. ${ }^{36}$

El último testimonio que analizaremos es la memoria de Jesús Manzanelli. Obrero y dirigente gremial, Manzanelli, junto a su hermano José, tuvieron una importante trayectoria en la lucha obrera y sindical de Córdoba. En especial, su impronta quedó marcada en huelgas destacadas de la época como la de la fábrica del calzado Céspedes y Tettamanti, en la ciudad de Córdoba, la del Sanatorio Santa María en la ciudad de Cosquin y la huelga denominada el Tampierazo en la ciudad de San Francisco. ${ }^{37}$

E1 ingreso a la política de Manzanelli tiene similitudes con el proceso experimentado por Burgas, pero en este caso, él y sus hermanos, primero se afiliaron al Partido Radical porque:

La primera Guerra Mundial y la profunda crisis de los años 1916 y 1918 conmovieron a las grandes masas populares a lo largo de todo el país. E1 Radicalismo se presentaba como una fuerza política contra la oligarquía. Postulaba los derechos y libertades del pueblo; prometía grandes cambios en las condiciones de vida de los

p. 55 .

36. Ídem, p. 54.

37. Véase sobre la biografía de Jesús Manzanelli: MANZANELLI, Jesús, La vida de un dirigente..., Op. Cit. También TARCUS, Horacio, Diccionario Biográfico..., Op. Cit. 
trabajadores...Estas razones influyeron para que los hermanos Manzanelli se afiliasen al Radicalismo. ${ }^{38}$

Nótese que para Manzanelli también el interés por la política se hace presente en el contexto de profunda crisis a raíz de la Primera Guerra Mundial y la Revolución Rusa. Su elección de ingresar a un partido político contiene criterios izquierdistas que fueron fundamentales para su iniciación en la militancia. Su primer contacto con un partido fue con el radicalismo porque este "se presentaba como una fuerza política contra la oligarquía, postulaba los derechos y libertades del pueblo". ${ }^{39}$ Esta diferenciación clasista que hace Manzanelli entre "ellos", la oligarquía, y "nosotros", el pueblo, está condicionada por un "lenguaje de clase", donde la oligarquía estaba conformada por los terratenientes, los dueños de los campos donde él y su familia habían sufrido la opresión y la explotación. En este sentido, la Unión Cívica Radical (en adelante, UCR) se presentaba como una opción anti-terrateniente y por ende anti-conservadora, ${ }^{40}$ de allí que este obrero se incorporara a las filas del radicalismo en primera instancia. Poco tiempo le llevó a Manzanelli darse cuenta que la UCR, más precisamente, Hipólito Irigoyen, traicionaría

38. MANZANELLI, Jesús, La vida de un dirigente..., Op. Cit., p.10.

39. Ibídem.

40. ROCK, David, El radicalismo argentino, 1890-1930,

Editorial Amarrortu, Buenos Aires, 2001 (tercera edición en castellano) capítulo 3. También véanse los escritos de la década de 1930 donde aparecen los términos oligarquía terrateniente y burguesía terrateniente.

Véase ODDONE, Jacinto, La burguesía terrateniente, Ediciones Libera, Buenos Aires, 1975, y HERNÁNDEZ ARREGUI, Juan José, La formación de la conciencia nacional, Ediciones Hachea, Buenos Aires, 1970, (segunda edición ampliada). su propia base social en la Semana Trágica y las huelgas patagónicas.

Este cambio decisivo en el carácter del gobierno radical llevó en el año 1919 a que Manzanelli se incorporara al PSI. Este rememoraba:

Por ese entonces yo y mis hermanos pertenecíamos al Radicalismo. Pero la huelga, la militancia en el sindicato, mi admiración por la Revolución Rusa, la profunda estimación y confianza que me inspiraban [Pablo] López y [Miguel] Contreras rápidamente me ganaron para la causa. Ya había empezado a leer $\mathrm{La}$ Internacional. En estas modestas cuatro páginas había un tesoro de claridad y orientación revolucionaria. Yo me sentía 'Socialista Internacional', 'maximalista'. ${ }^{41}$

Como puede observarse en este fragmento, varios elementos se combinaron para que Manzanelli se incorporara a las filas de un partido de izquierda y que se convirtiera, junto a sus hermanos, en "maximalista". De nuevo la lectura, en este caso del periódico comunista La Internacional, sumado a la experiencia en el sindicato, la admiración por la Revolución Rusa, la confianza y estimación en compañeros como Pablo López y Miguel Contreras, definieron el ingreso a la política de Manzanelli. Para él era "natural" que un obrero fuera comunistas, o como expresaba, "Socialista Internacional", o "maximalista", y esto lo revalida la Revolución Rusa.

La lucha obrera y sindical completa este proceso de politización en Manzanelli. Prestemos atención al siguiente fragmento de su memoria:

41. MANZANELLI, Jesús, La vida de un dirigente..., Op. Cit., p. 20. 
A principio del año 1918 tenía por entonces 21 años y trabajaba desde hacía unos años en la fábrica de calzado de la firma 'Céspedes Tettamanti y Cía'... Entre los obreros de esta firma se acentuaba un clima de agitación y rebeldía contra los bajos salarios, los despidos injustos y la brutal prepotencia patronal... Un día lunes a la mañana, en los alrededores de la fábrica, un piquete de obreros invitaba a no entrar y 'sumarnos a la huelga'. Todo el personal respondió unánimemente. De inmediato todos se trasladaron al local del Sindicato para discutir el 'Pliego de Condiciones'que se presentaría a los patrones. Por la tarde la casi totalidad de los obreros se reunían en asamblea con los personales de otras fábricas menores. La huelga era ya un hecho contundente... El pliego establecía un $30 \%$ de aumento de salario, jornada de 8 horas y sábado inglés, reconocimiento del sindicato y del feriado del $1^{\circ}$ de mayo. La huelga duró más de un mes por la tozuda intransigencia patronal. En el transcurso de esa huelga se desplegó una permanente agitación y movilización obrera... En el transcurso de la huelga se conformó el Sindicato 'Unión General de Obreros en Calzado'. Pero lo más importante de esta huelga fue que los dirigentes de la 'Unión Obrera Local' de Córdoba, especialmente (Pablo) López y (Miguel) Contreras apoyaron nuestro movimiento, reclamando la solidaridad con mítines y manifestaciones, abriendo el cauce para la organización de otros gremios que se lanzaron a la lucha... Esta huelga fue para mí un acontecimiento nuevo y extraordinario, cambió el curso de mi vida. Desde este momento no fui un simple obrero más. Había comprendido que pertenecía a una clase social, la clase obrera. Había aprendido lo que representa el sindicato, la unidad, la solidaridad y la lucha. ${ }^{42}$

42. Ídem, pp. 13-15.
Quedaría claro en este segmento de las memorias de este comunista cómo la experiencia de la huelga, la lucha y el trabajo en el sindicato constituyeron su ingreso a la militancia, ya a un partido de izquierda. Manzanelli lo expone de manera explícita al decir que "la huelga fue un acontecimiento extraordinario" que le cambió la vida y la forma de percibir el mundo. De ahora en más no sería un simple obrero, la lucha lo había ayudado a entender que pertenecía a una clase social, la clase obrera. Su politización culminó con su incorporación en el PC. Este militante lo expresaba diciendo que "fuimos una familia muy religiosa, pero las duras experiencias de la vida, las injusticias sociales, las huelgas, la lucha en el sindicato, los libros y finalmente las enseñanzas del Partido Comunista hicieron polvo las viejas creencias". ${ }^{43}$

En las memorias de Manzanelli podemos trazar cómo fue el proceso de politización de este comunista, en un contexto de efervescencia de la lucha obrera y sindical.Para él, la Revolución Rusa era lo que impulsaba este auge del movimiento obrero de Córdoba ya que "era la llama ardiente que inflamaba a la clase obrera y las masas populares, la grandiosa Revolución Proletaria de Rusia que había instalado el primer gobierno de obreros y campesinos y establecido el principio, jamás conocido de: “¿Quién no trabaja no come!”. ${ }^{4}$

En estas breves líneas se resume lo que significó la revolución para un obrero y dirigente comunista cordobés, la llama ardiente de un movimiento que trascendió sus fronteras y les dio identidad a quienes por
43. Ídem, p. 8.

44. Ídem, p. 18. 
esa época se sintieron "maximalistas", a miles de kilómetros de Rusia.

\section{Conclusiones}

Como hemos podido apreciar, la Revolución Rusa tuvo un gran impacto en los testimonios analizados. A través de las memorias de Miguel Contreras, Miguel Burgas y Jesús Manzanelli, pudimos indagar cómo la revolución tuvo un papel preponderante en las primeras décadas del siglo XX en Córdoba, donde el movimiento obrero y sindical estaba dando sus primeros pasos. En este ambiente de movilización popular, la revolución de octubre fue vista entre estos nuevos militantes del naciente PC como "la llama ardiente que inflamaba a la clase obrera", como una guía para la acción. De esta manera, se apropiaron del ideario revolucionario, convirtiendo a estos militantes en artífices del movimiento popular que se estaba gestando. Diferentes fueron las experiencias vividas y registradas en las memorias de Miguel Contreras, Miguel Burgas y Jesús Manzanelli. Esto se debió al lugar que cada uno ocupó dentro del naciente Partido Comunista cordobés, como así también, a la relevancia que tuvo el movimiento revolucionario en sus propios procesos de politización. En el caso de Contreras, la Revolución Rusa tuvo un lugar destacado, no solo en lo particular, sino también en el movimiento obrero y sindical. En este sentido, su experiencia personal se encuentra íntimamente imbricada en un proceso que no distingue entre su ingreso a la militancia (primero en el Partido Socialista y luego como fundador del PSI) con el surgimiento del movimiento obrero que se estaba organizando. En su relato, él se convierte en vanguardia del proceso revolucionario, siendo un protagonista clave del mismo. Esto se debería a su rol en la conformación del partido en Córdoba y también su participación tanto a nivel nacional como internacional, en cargos importantes. En un plano diferente, se pueden ubicar las memorias de Burgas y Manzanelli. Para estos militantes, la Revolución Rusa se puede tomar como un parte aguas, siendo determinante en su proceso de politización. De esta manera, el maximalismo se convirtió en una opción frente a otras experiencias partidarias como el socialismo y el radicalismo, partidos por donde estos militantes habían comenzado su militancia. Su politización también aquí se complejiza, ya que también se produjo un proceso de toma de conciencia de clase en "si" a clase "para sí". Parafraseando a Jesús Manzanelli, "desde este momento no fui un simple obrero más. Había comprendido que pertenecía a una clase social, la clase obrera". ${ }^{45}$ En estos ejemplos podemos analizar no sólo el impacto que la Revolución Rusa tuvo sobre las personas, sino también cómo se convierte, junto a otros medios de sociabilidad como la discusión y la lectura, en elementos a considerar en los procesos de politización y el ingreso a la militancia, en este caso, de un partido de izquierda.

En un contexto de auge de la izquierda a nivel nacional como provincial, como fue la década de 1920, estos militantes se consideraron como "verdaderos revolucionarios" e hicieron del ideario del maximalismo una bandera propia, cuya meta era la construcción de un mundo mejor. La Revolución Rusa era la muestra de que ese sueño era posible.

45. Idem, p. 15. 
$\infty \ddot{\ell} \sim$

Recibido: 17-02-2017

Aceptado: 04-08-2017

Publicado: 05-12-2017 


\section{Bibliografía}

BILSKY, Edgardo J., La Semana Trágica, Centro Editores de América Latina, Buenos Aires, 1984.

BURGAS, Miguel, El primer diputado comunista. Año 1924, Editorial Anteo (Colección Testimonios), Buenos Aires, 1985.

CAMARERO, Hernán, A la conquista de la clase obrera. Los comunistas y el mundo del trabajo en la Argentina, 1920-1935, Editorial Siglo XXI, Buenos Aires, 2007.

CAMPIONE, Daniel, El Comunismo en Argentina. Sus primeros pasos, Centro Cultural de la Cooperación Floreal Gorini, Buenos Aires, 2005.

CONTRERAS, Miguel, Memorias, Colección Testimonios, Buenos Aires, 1978.

CORBIÈRE, Emilio, Orígenes del comunismo argentino, Centro Editor de América Latina, Buenos Aires, 1984.

DANIELE, Flavia, Historia de la primera intendencia comunista de la provincia de Córdoba. El Block obreros y campesinos de Villa Huidobro: 1925-1928, Tinta Libre, Córdoba, 2011.

FERRERO, Roberto, "Pablo B. López, líder del proletariado de Córdoba”, en Revista Deodoro, Córdoba, 2010, No 3, p. 11.

HERNÁNDEZ ARREGUI, Juan José, La formación de la conciencia nacional, Ediciones Hachea, Buenos Aires, 1970, (segunda edición ampliada).

HOBSBAWM, Eric J., Revolucionarios. Ensayos contemporáneos, Editorial Ariel, Barcelona, 1978.

ISCARO, Rubens, Origen y desarrollo del movimiento sindical argentino, Editorial Anteo, Buenos Aires, 1958.

MANZANELLI, Jesús, La vida de un dirigente obrero y comunista cordobés, Colección Testimonios, Buenos Aires, 1971.

MASTRÁNGELO, Mariana, Cultura y politica en la Argentina: los comunistas en la buelga de 1929 en San Francisco, una ciudad del interior de Córdoba, Facultad de Filosofía y Letras, Universidad de Buenos Aires/ Editorial Imago Mundi, Buenos Aires, 2006.

MASTRÁNGELO, Mariana, Rojos en la Córdoba obrera, 1930-1940, Imago Mundi, Buenos Aires, 2011.

MASTRÁNGELO, Mariana, "Biografía de Miguel Burgas, el primer diputado comunista argentino" en GODHINO Paula, FONSECA Inés, y BAÍA Joao (coordinadoras) Resistencia e/y Memoria. Perspectivas iberoamericanas (Documento electrónico). IHC-FCSH/UNL, Lisboa, 2014, pp. 142-151.

ODDONE, Jacinto, La burguesía terrateniente, Ediciones Libera, Buenos Aires, 1975. 
ROCK, David, El radicalismo argentino, 1890-1930, Editorial Amarrortu, Buenos Aires, 2001 (tercera edición en castellano).

SÁ AVELAR, Alexandre y BISSO SCHMIDT, Benito (compiladores) Grafía da vida. Reflexóes e experiencias com a escrita biográfica, Letra e Voz, Sao Paulo, 2012.

TARCUS, Horacio, Diccionario Biográfico de la izquierda argentina, Emecé Editores, Buenos Aires, 2007.

WILLIAMS, Raymond, Marxismo y literatura, Barcelona, Ediciones Península, 1980. 